\title{
Burst capacity analysis of pipeline with multiple longitudinally aligned interacting corrosion defects subjected to internal pressure and axial compressive stress
}

\author{
Thibankumar Arumugam ${ }^{1} \cdot$ Muhammad Kasyful Azhim Mohamad Rosli ${ }^{1}$. Saravanan Karuppanan ${ }^{1}$. \\ Mark Ovinis ${ }^{1} \cdot$ Michael Lo ${ }^{1}$
}

Received: 23 February 2020 / Accepted: 29 May 2020 / Published online: 11 June 2020

(c) Springer Nature Switzerland AG 2020

\begin{abstract}
This paper describes the application of finite element method (FEM) to predict the failure pressure of corrosion-affected pipes, specifically for pipes with multiple internal ( 2 and 3 defects) longitudinally aligned interacting corrosion defects subjected to internal pressure and axial compressive stress. The FEM was verified against results of full-scale burst tests. The developed FEM incorporated material nonlinearity, which allows for large strains and displacements. Furthermore, true ultimate tensile strength (UTS) instead of the typical engineering UTS was employed to determine the point of failure. The pipes used in the finite element analysis (FEA) were modeled based on API 5L X52 with a length of $2000 \mathrm{~mm}$, a nominal outer diameter of $300 \mathrm{~mm}$, and a nominal wall thickness of $10 \mathrm{~mm}$. The results obtained from the FEA were presented in a graph form and then used to determine the failure pressure trendlines of multiple longitudinally aligned interacting corrosion defects for varying defect depths and spacing between defects. In addition, the failure pressure trendlines of multiple longitudinally aligned interacting defects were compared to determine their differences. As expected, 3 longitudinally aligned interacting defects showed lower failure pressure compared to 2 longitudinally aligned interacting defects.
\end{abstract}

Keywords Pipe corrosion · Multiple corrosion defect · Internal pressure · Axial compressive stress · Finite element analysis

\section{Introduction}

Pipelines are one of the facilities used both offshore and onshore to transport hydrocarbons from the well reservoir up to the topside facilities and further to onshore facilities. It serves as arteries in oil and gas industry and has been widely accepted as one of the most economical ways of transporting oil and gas over long distance [1]. The strength of the pipeline is the main concern as it determines its service lifespan. However, the harsh working environment can rapidly deteriorate the integrity of the pipelines.
The pipelines are generally exposed to both internal and external corrosion. Corrosion is defined as a reduction or destruction of materials due to electrochemical reactions with the surrounding environment. Although the pipelines have corrosion-preventive measures such as cathodic prevention methods during the installation, the protection may be damaged due to the harsh working environment. In addition to corrosion damage, pipelines which are installed at regions with ever-changing land conditions are exposed to axial compressive loadings which when imposed on corrosion-affected pipelines can lead to many types of failure modes including and not limited to bursting and buckling [2].

Saravanan Karuppanan, saravanan_karuppanan@utp.edu.my $\mid{ }^{1}$ Mechanical Engineering Department, Universiti Teknologi PETRONAS, 32610 Bandar Seri Iskandar, Perak, Malaysia. 


\subsection{Interacting corrosion defects}

There are two common classifications of corrosion defects, one is single defect and the other being interacting defects. Single defect is when a corrosion defect is sufficiently isolated that its imposed stress and strain do not interact with any adjacent corrosion defects. In contrast, interacting defects are when corrosion defects are sufficiently close to each other causing stress and strain interaction, may it be in circumferential or longitudinal direction. This work specially focuses on multiple ( 2 and 3 defects) longitudinally aligned interacting corrosion defects. Longitudinally aligned interacting corrosion defects are characterized by full-wall thickness separation in the longitudinal direction of the pipe.

In most cases, the failure pressure caused by interacting corrosion defects is far lower compared to the failure pressure caused by a single corrosion defect. This is due to the complex interaction behavior when stress and strain disruptions occur on at least one of the corrosion defects. Each corrosion defect imposes its own stress and strain disturbances. These stress and strain disturbances expand out from the corrosion defects. The regions of expansion of the stress and strain disturbances are known as regions of corrosion defects. The overlapping of regions of adjacent interacting corrosion defects is the main cause for the significant decrease in failure pressure

\subsection{Critical interacting corrosion defect parameters}

There are many corrosion defect parameters that affect the final failure pressures, such as defect depth, defect length, defect width and defect spacing. However, this study focuses on two of the critical parameters which are the defect depth and defect spacing. Defect depth is the most significant factor as proven by a study conducted by Netto et al. [3]. The study compared the failure pressure of AISI 1020 Mild Steel pipes for varying defect depths and lengths. The study revealed a $18 \%$ decrease in failure pressure when the defect depth was increased by $0.2 t$, while there was only a $14 \%$ decrease in failure pressure when the defect length was doubled from $0.5 D$ to $1.0 D$.

In cases involving interacting corrosion defects, defect spacing is an important parameter. Study conducted by Li et al. [4] revealed that corrosion defects that are at close proximity to each other tend to have lower failure pressure compared to when they are single and isolated. It was also determined that when the defect spacing exceeded a normalized defect spacing value of 2.0, the interacting behavior plateaus thus revealing the limit of interaction for longitudinally aligned interacting defects. This limit value is also in line with the guideline set by DNV-RP-F101 [5].

\subsection{Effect of axial compressive stress}

The effect of axial compressive stress has only been sparsely researched despite its known detrimental effects. Often in pipelines, axial compressive stress occurs due to the Poisson's effect as a result of the increase in circumferential expansion caused by the increase in internal pressure [6]. In addition, the increase in transport fluid temperature [6] as well as local geological events (i.e., landslides, earthquakes, mining subsidence) have shown to impose axial compressive stress on pipelines [7-9]. A study conducted by Chauhan et al. [7] on single defect subjected to internal pressure and axial compressive stress revealed that the additional axial compressive stress does adversely affect the failure pressure of the pipe. Results from the study also revealed that buckling failure was more prominent for shallow defects, where failure was governed by global instability instead of local instability (failure due to burst). Xu and Cheng [9] studied the effects of tensile and compressive strain on corrosion-affected pipes. The FEA study revealed that the failure pressure was adversely affected, regardless of the type of external axial loading (tensile or compressive). This finding is also supported by Cosham and Hopkins [10], Cosham et al. [11], Bjørnøy et al. [12], and Bjørnøy et al. [13].

In this study, a detailed FEM to simulate and predict the failure pressure of multiple longitudinally aligned interacting defects subjected to internal pressure and axial compressive stress is presented. Results obtained from the FEM were used to determine the differences in trends between 2 and 3 longitudinally aligned interacting defects subjected to internal pressure and axial compressive stress.

\section{Methodology}

\subsection{Overview of corrosion defect parametric values}

The parametric study conducted in this work was based on the geometric values shown in Table 1. Only the defect depth, $d$, and defect spacing, s, were varied in this study, and they are presented as normalized values. These defects were then subjected to varying axial compressive stress, $\sigma_{c}$. The defect length, $I$, and defect width, $w$, were set constant throughout the study.

\subsection{Finite element method}

Several assumptions and simplifications were made during the development of the FEM. First, the corrosion defects were assumed to be rectangular (rectangular defect idealization) as it has been proven to give reasonable accuracy 
Table 1 Geometric parameters for the parametric study

\begin{tabular}{ll}
\hline Input parameters & Values \\
\hline Diameter of pipe, $D(\mathrm{~mm})$ & 300 \\
Length of pipe, $L(\mathrm{~mm})$ & 2000 \\
Wall thickness of pipe, $t(\mathrm{~mm})$ & 10 \\
Normalized defect length, $I / D$ & 1.0 \\
Normalized defect width, $w / t$ & 10 \\
Normalized defect depth, $d / t$ & $0.2,0.4,0.6$ \\
Normalized defect spacing, $s / \sqrt{D t}$ & $0.25,0.5,1,2,4,6$ \\
Normalized axial compressive stress, $\sigma_{c} / \sigma_{y}$ & $0,0.4,0.6$ \\
\hline
\end{tabular}

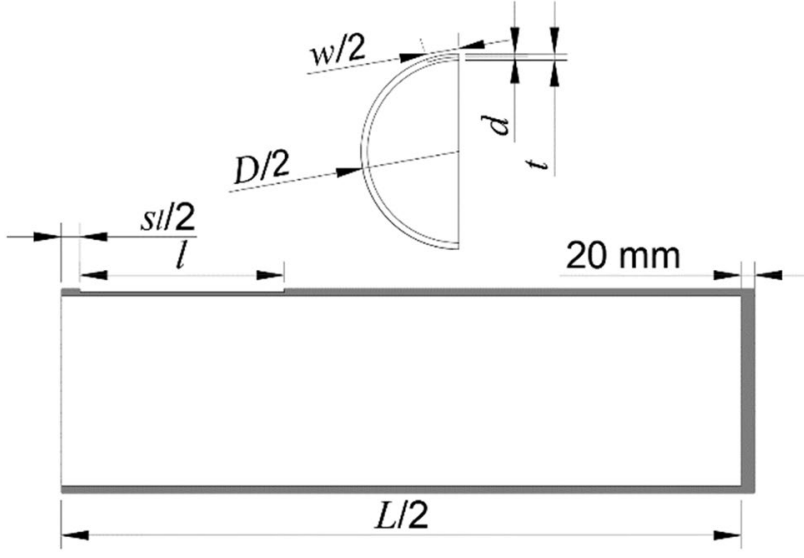

Fig. 1 Annotated symmetrical quarter model with 2 longitudinally aligned interacting corrosion defects

when predicting failure pressure of corroded pipelines [3]. The corrosion defect was designed on the external surface of the pipe; however, this is a nonissue as it has been noted that internal corrosion and external corrosion in pipeline have no difference in failure behavior [11]. Next, a symmetrical quarter model was used as it reduces the simulation time without compromising the results obtained from the finite element analysis (FEA). The method of using a symmetrical quarter model has been successfully employed by Belachew et al. [14] for pipelines with single corrosion defect subjected to internal pressure. For this study, Autodesk AutoCAD was used to design a symmetrical quarter model to represent the actual pipe geometry. Figure 1 illustrates an annotated example of a symmetrical quarter model used in the developed FEM. The pipes were designed with a length of $2000 \mathrm{~mm}$ as well as an additional $20 \mathrm{~mm}$ acting as the rigid body section of the pipe. The rigid body section of the pipe allows for equal distribution of the axial compressive stress on the pipe wall.

Since symmetrical quarter models were used, appropriate boundary conditions were applied at the necessary regions so that the quarter model would be treated as a whole model. Figure 2 illustrates the region in red where symmetrical boundary conditions were applied. The DOF of the quarter models were constrained to prevent unwanted rigid body motions. Referring to the yellow region in Fig. 2, the DOF was constrained in the $x$ and $y$ directions which allows movement in the axial axis ( $z$ direction).

For this simulation study, ANSYS 16.1 APDL (ANSYS) was used to predict the failure pressure of corroded pipes. In this study, hexahedral SOLID185 elements were chosen for meshing of the corroded pipes. An illustration of the application of SOLID185 is shown in Fig. 3. Tetrahedral SOLID186 elements were chosen for meshing of the rigid body. SOLID186 elements allow for meshing of curved boundaries. An illustration of the application of SOLID186 is shown in Fig. 4. It was recommended by British Standard Institute [15] that at least 2 to 4 layers of elements were to be meshed at the corrosion defect region to ensure accurate failure pressure prediction. Thus, in this study, 3 layers of elements were meshed at the defect regions, while 6 layers of elements were meshed at regions between the defects. The width and length of the mesh were set to be $2 \mathrm{~mm}$, respectively. Mesh bias was set away from the defect regions to reduce the total number of elements used,
Fig. 2 Application of symmetrical boundary conditions, DOF constraints, internal pressure and axial compressive stress

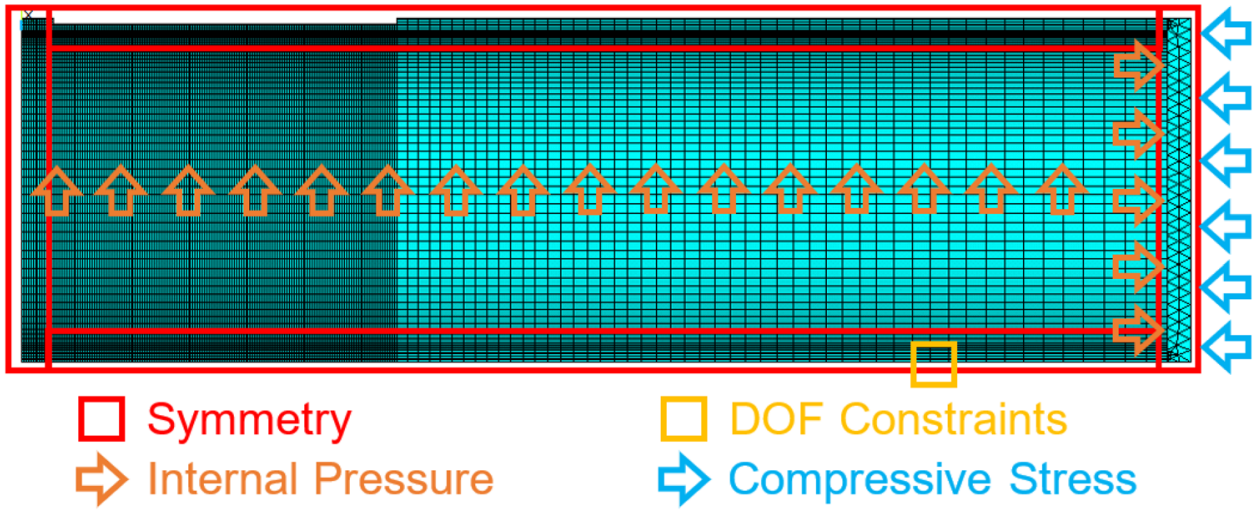

SN Applied Sciences A SPRINGER NATURE journa 


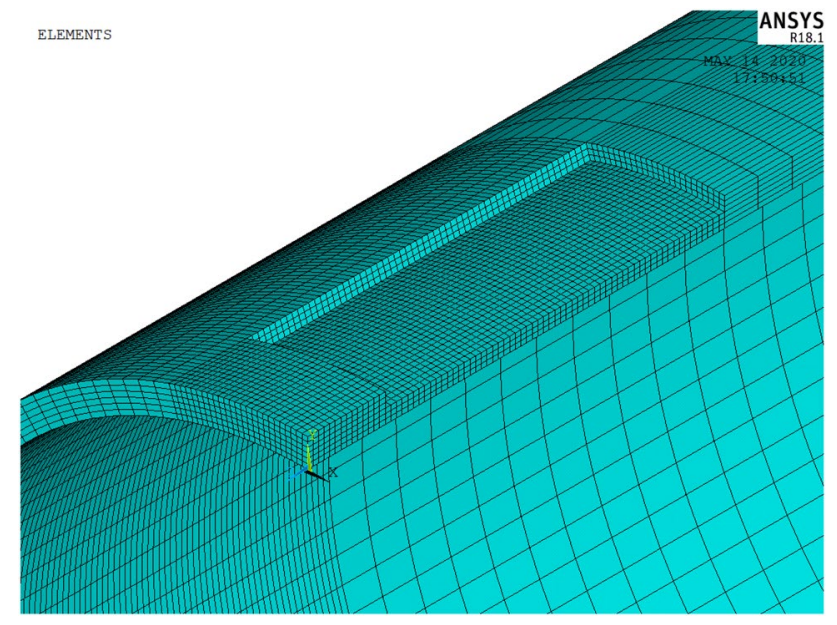

Fig. 3 Application of SOLID185 on a model with 2 longitudinally aligned interacting corrosion defects
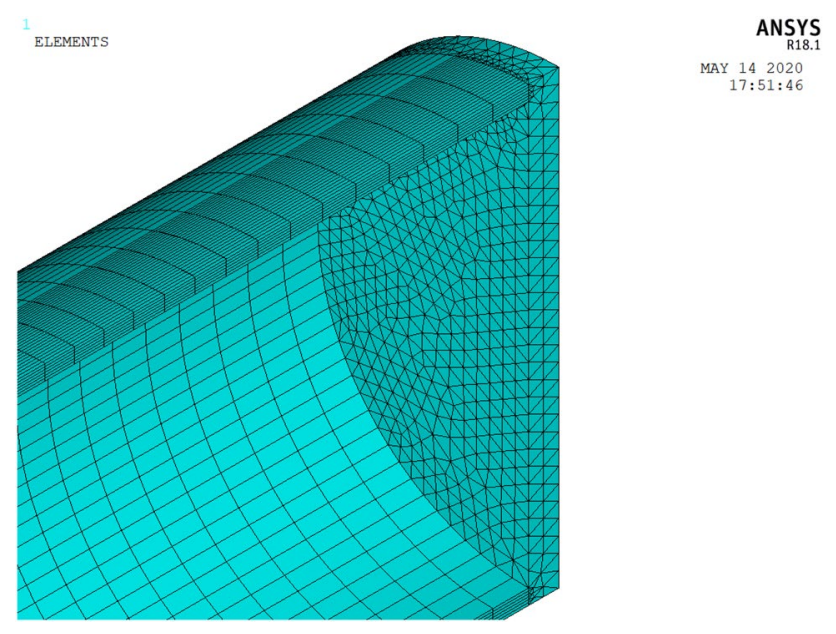

Fig. 4 Application of SOLID186 on the rigid body

thus, reducing the simulation time. As shown in Table 2, results of the convergence study revealed that 3 layers were adequate as higher number of layers resulted in an exponential increase in simulation time without much gain on the accuracy of the result. Note that the convergence study was conducted on a pipe with a corrosion $d / t=0.5$ and $I / D=0.6$. In addition, the failure pressure of intact pipe, $P_{i}$, was determined to be $43.71 \mathrm{MPa}$.

To determine the failure pressure of corroded pipe, an iterative method was performed by ANSYS. The incremental form of the governing equation as per Eq. 1 was utilized to achieve the solution for the nonlinear governing equation.

$K(u) \Delta u=\Delta P$
Table 2 Number of element layers at the defect region with the corresponding FEA results

\begin{tabular}{ll}
\hline No. of element layers at defect region & $\begin{array}{l}\text { Normalized } \\
\text { failure pressure, } \\
P_{f} / P_{i}\end{array}$ \\
\hline 1 & 0.50 \\
2 & 0.52 \\
3 & 0.53 \\
4 & 0.53 \\
5 & 0.53 \\
6 & 0.53 \\
\hline
\end{tabular}

ANSYS utilizes the Newton-Raphson method, which is a series of iterative linear steps taken in appropriate direction to obtain a closer approximation to the exact solution of a nonlinear problem. Based on Eq. (2) and Eq. (3), the iterative procedures begin with solution assumption and identification of increment magnitude, respectively. Then, Eq. (4) is applied to evaluate the difference of the applied load and the load evaluated based on the assumed solution which is known as the corresponding out-of-balance load vector. The out-of-balance load vector must be zero in order to fulfill the equilibrium conditions.

$u=u_{i}$

$\Delta u_{i}=K^{-1}\left(u_{i}\right) \Delta P$

$\Delta R_{i}=\Delta P-K\left(u_{i}\right) \Delta u_{i}$

The iterative procedure will keep on looping because it is impossible to ensure the out-of-balance load vector to be exactly zero. Therefore, a tolerance is introduced for the outof-balance load vector after the nonlinear equilibrium conditions are solved approximately to zero so that the iterative procedure can terminate. Based on the specified tolerance, the convergence criterion for the out-of-balance load vector is checked and the trial solution is updated if the convergence criterion failed. Hence, the next incremental solution vector based on the calculated incremental displacement leading to the computation of the new out-of-balance load vector is identified based on Eqs. 5, 6, and 7. The following procedures are repeated until the convergence criterion is achieved. In order to improve the convergence behavior, options such as time stepping, bisection method, and line search algorithm method can be employed as well.

$u_{i+1}=u_{i}+\Delta u_{i}$

$\Delta u_{i+1}=K^{-1}\left(u_{i+1}\right) \Delta P$ 
$\Delta R_{i+1}=\Delta P-K\left(u_{i+1}\right) \Delta u_{i+1}$

The load applications were controlled via timestep for this static nonlinear analysis. First, axial compressive stress was applied incrementally at the external surface of the rigid body section as depicted by the blue arrows in Fig. 2. Then, while maintaining the axial compressive stress, internal pressure was applied incrementally to the internal surface of the model as depicted by the orange arrows in Fig. 2. A timestep of 500 was set for both loads to allow for accurate FEA as well as to prevent elements undergoing high distortions, especially when high axial compressive stress loads are imposed.

\subsection{Material properties}

The material properties of the pipes modeled in this FEM were based on the nonlinear true stress-strain curve of API $5 \mathrm{~L}$ X52 steel (medium toughness), as shown in Fig. 5. The ultimate tensile stress, $\sigma_{\mathrm{UTS}}$, is $514 \mathrm{MPa}$, while the true ultimate tensile stress, $\sigma_{\mathrm{UTS}}^{*}$, is $612 \mathrm{MPa}$ at a strain value of 0.1745 . To account for high material nonlinearity during the FEA, large strain and displacements, as well as material

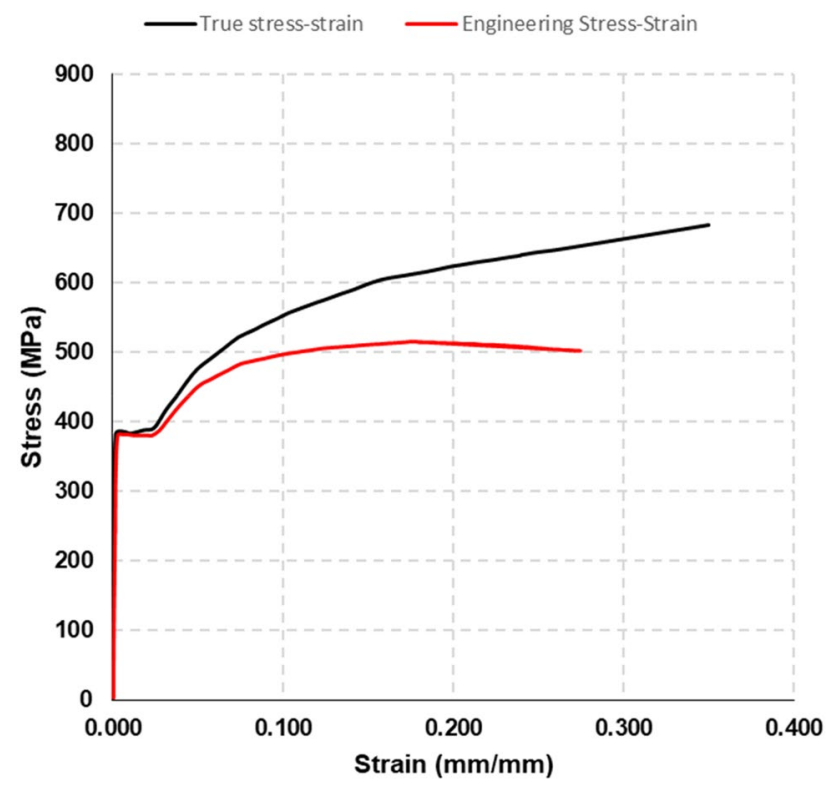

Fig. 5 True stress-strain curve for API 5L X52 steel [16] stress stiffening, were considered. In addition to that, rateindependent plasticity model that uses the von Mises yield criterion and isotropic hardening rule was employed. For the pipe material, the modulus of elasticity and Poisson's ratio were set as $200 \mathrm{GPa}$ and 0.3 , respectively, while for the rigid body material, the modulus of elasticity and Poisson's ratio were set as $200 \mathrm{TPa}$ and 0.3 , respectively.

\subsection{Failure criterion}

Stress-based criterion was employed in this study to determine the onset of failure. Failure is said to occur when the local stress at the defect area exceeds the specified stress, as per DNV-RP-F101 [5]. In this study, when the von Mises stress throughout the pipe ligament is equal to the $\sigma_{U T S^{\prime}}^{*}$ the pipe is said to have undergone failure, and the corresponding applied internal pressure can be defined as the failure pressure. The prediction of failure pressure based on $\sigma_{\text {UTS }}^{*}$ provides a much accurate result compared to $\sigma_{y}$ because the failure mechanism is often governed by plastic collapse [13].

\section{Methodology verification}

Study conducted by Ma et al. [17] included a compilation of full-scale burst test results of corroded pipe with single defect subjected to internal pressure only. For brevity, only 2 of the full-scale burst test results were used to verify the performance of the developed FEM. Before moving on to the methodology verification, an overview of the fullscale burst tests will be outlined. The full-scale burst tests were conducted on API $5 \mathrm{~L} \mathrm{X65}$ steel pipes with a nominal thickness of $17.5 \mathrm{~mm}$ and a nominal diameter of $762 \mathrm{~mm}$. Table 3 lists the dimensions of the artificially machined corrosion defects, failure pressure of the full-scale burst tests, FEA failure pressure predictions, and the absolute percentage difference between both failure pressure values. The failure pressure predictions have a maximum of $3.14 \%$ difference which is well within the accuracy limit of $10 \%$.

Study conducted by Benjamin et al. [18] included a full-scale burst tests of corroded pipe with both single and interacting defects subjected to internal pressure only. Before moving on to the methodology verification,
Table 3 Tabulation of corrosion defect parameters and failure pressure obtained using the developed FEM and the full-scale burst tests compiled by Ma et al. [17]

\begin{tabular}{lllllll}
\hline Test number & $I(\mathrm{~mm})$ & $d(\mathrm{~mm})$ & $w(\mathrm{~mm})$ & $\begin{array}{l}\text { Full-scale burst test } \\
\text { failure pressure (MPa) }\end{array}$ & $\begin{array}{l}\text { FEA failure } \\
\text { pressure } \\
(\mathrm{MPa})\end{array}$ & $\begin{array}{l}\text { Absolute per- } \\
\text { centage differ- } \\
\text { ence (\%) }\end{array}$ \\
\hline 64 & 100 & 8.80 & 100 & 24.30 & 24.61 & 1.26 \\
65 & 200 & 8.80 & 200 & 19.08 & 19.70 & 3.14 \\
\hline
\end{tabular}


Table 4 Tabulation of corrosion defect parameters and failure pressure obtained using the developed FEM and the full-scale burst tests compiled by Benjamin et al. [18]

\begin{tabular}{lllllllll}
\hline Test number & $I(\mathrm{~mm})$ & $d(\mathrm{~mm})$ & $w(\mathrm{~mm})$ & $\begin{array}{l}\text { Long. spac- } \\
\text { ing }(\mathrm{mm})\end{array}$ & $\begin{array}{l}\text { Circ. spac- } \\
\text { ing }(\mathrm{mm})\end{array}$ & $\begin{array}{l}\text { Full-scale burst test } \\
\text { failure pressure }(\mathrm{MPa})\end{array}$ & $\begin{array}{l}\text { FEA failure } \\
\text { pressure (MPa) }\end{array}$ & $\begin{array}{l}\text { Absolute per- } \\
\text { centage differ- } \\
\text { ence }(\%)\end{array}$ \\
\hline 2 & 39.6 & 5.39 & 31.9 & - & - & 22.68 & 22.40 & 1.23 \\
3 & 39.6 & 5.32 & 31.9 & 20.5 & - & 20.31 & 20.00 & 0.02 \\
4 & 39.6 & 5.62 & 32.0 & - & 9.9 & 21.14 & 22.10 & 4.55 \\
\hline
\end{tabular}

Table 5 Tabulation of corrosion defect parameters and failure pressure obtained using the developed FEM and the full-scale burst tests by Bjørnøy et al. [19]

\begin{tabular}{llllllll}
\hline Test number & $I(\mathrm{~mm})$ & $d(\mathrm{~mm})$ & $w(\mathrm{~mm})$ & $\begin{array}{l}\sigma_{c} \\
(\mathrm{~mm})\end{array}$ & $\begin{array}{l}\text { Full-scale burst test } \\
\text { failure pressure } \\
(\mathrm{MPa})\end{array}$ & $\begin{array}{l}\text { FEA failure } \\
\text { pressure } \\
(\mathrm{MPa})\end{array}$ & $\begin{array}{l}\text { Absolute per- } \\
\text { centage differ- } \\
\text { ence }(\%)\end{array}$ \\
\hline 5 & 100 & 8.80 & 100 & 48.0 & 28.60 & 29.40 & 2.80 \\
6 & 200 & 8.80 & 200 & 84.0 & 28.70 & 29.10 & 1.40 \\
\hline
\end{tabular}

an overview of the full-scale burst tests will be outlined. The full-scale burst tests were conducted on API $5 \mathrm{~L} \mathrm{X80}$ steel pipes with a nominal thickness of $8.1 \mathrm{~mm}$, and a nominal diameter of $762 \mathrm{~mm}$. Table 4 lists the dimensions of the artificially machined corrosion defects, failure pressure of the full-scale burst tests, FEA failure pressure predictions, and the absolute percentage difference between both failure pressure values. The failure pressure predictions have a maximum of $4.55 \%$ difference which is well within the accuracy limit of $10 \%$.

Study conducted by Bjørnøy et al. [19] included a fullscale burst tests of corroded pipe with single defect subjected to internal pressure and axial compressive stress. Similarly, for brevity, only 2 of the full-scale burst tests were used to verify the performance of the developed FEM. Before moving on to the methodology verification, an overview of the full-scale burst tests will be outlined. The full-scale burst tests were conducted on API $5 \mathrm{~L} \mathrm{X52}$ steel pipes with a nominal thickness of $10.3 \mathrm{~mm}$ and a nominal diameter of $324 \mathrm{~mm}$. Table 5 lists the dimensions of the artificially machined corrosion defects, the axial compressive stress application, failure pressure of the full-scale burst tests, FEA failure pressure predictions, and the absolute percentage difference between both failure pressure values. The failure pressure predictions have a maximum of $2.80 \%$ difference which is well within the accuracy limit of $10 \%$. It should be noted that despite the significant increase in application of axial compressive stress to Test 6 , the failure pressure between Tests 5 and 6 is relatively the same.

In order to further validate the developed FEM, the outputs of the FEM were compared with the results obtained using the thin-walled pressure vessel theory. The FEM outputs of interest are the hoop stress, $\sigma_{h}$ and longitudinal stress,
Table 6 Tabulation of hoop stress and longitudinal stress of pristine pipe obtained via theoretical calculation and FEA

\begin{tabular}{|c|c|c|c|c|c|}
\hline \multicolumn{2}{|c|}{ Theoretical calculation } & \multicolumn{2}{|c|}{ FEA prediction } & \multicolumn{2}{|c|}{$\begin{array}{l}\text { Absolute percent- } \\
\text { age difference (\%) }\end{array}$} \\
\hline $\begin{array}{l}\text { Hoop } \\
\text { stress } \\
\text { (MPa) }\end{array}$ & $\begin{array}{l}\text { Long. } \\
\text { stress } \\
(\mathrm{MPa})\end{array}$ & $\begin{array}{l}\text { Hoop } \\
\text { stress } \\
(\mathrm{MPa})\end{array}$ & $\begin{array}{l}\text { Long. } \\
\text { stress } \\
(\mathrm{MPa})\end{array}$ & $\begin{array}{l}\text { Hoop } \\
\text { stress } \\
(\mathrm{MPa})\end{array}$ & $\begin{array}{l}\text { Long. } \\
\text { stress } \\
\text { (MPa) }\end{array}$ \\
\hline 140.00 & 32.30 & 135.80 & 33.24 & 3.00 & 2.91 \\
\hline
\end{tabular}

$\sigma_{l}$. Without the influence of the corrosion defect, the FEM should output results that are close to that of theoretical calculations. The theoretical values of the hoop stress and longitudinal stress can be determined using Eqs. (8) and (9), respectively. Note that $P_{i}$ is the failure pressure of intact pipe, while $r$ is the internal radius of the pipe.

$\sigma_{h}=\frac{P_{i} r}{t}$

$\sigma_{l}=\frac{P_{i} r}{2 t}$

By referring to Table 6 , the percentage difference of values obtained from theoretical calculations and FEA is approximately $3 \%$. 


\section{Results and discussion}

\subsection{Results obtained from FEA}

The results of the FEA are presented in Table 7. For conciseness, results are presented as graphs to clearly understand and distinguish the failure pressure trends of various corrosion defect parameters, as well as external load. The abbreviations of 2 LAID and 3 LAID refer to 2 and 3 longitudinally aligned interacting defects, respectively. Note that the failure pressure predictions are presented as normalized values where the failure pressure of intact pipe, $P_{i}$, is $43.71 \mathrm{MPa}$.

\subsection{Effects of axial compressive stress}

Referring to Fig. 6a, it is quite apparent that there are differences and similarities between failure pressure obtained from 2 LAID as well as 3 LAID. Referring to the trendlines, when the multiple longitudinally aligned interacting defects are subjected to internal pressure only, 2 LAID present higher failure pressure compared to 3 LAID. Computation of the failure pressure percentage difference between
Table 7 Tabulation of FEA results obtained using the developed FEM for 2 LAID and 3 LAID

\begin{tabular}{|c|c|c|c|c|c|c|c|}
\hline \multicolumn{4}{|c|}{2 LAID } & \multicolumn{4}{|c|}{3 LAID } \\
\hline$d / t$ & $s / \sqrt{D t}$ & $\sigma_{c} / \sigma_{y}=0.4$ & $\sigma_{c} / \sigma_{y}=0.6$ & $d / t$ & $s / \sqrt{D t}$ & $\sigma_{c} / \sigma_{y}=0.4$ & $\sigma_{c} / \sigma_{y}=0.6$ \\
\hline 0.2 & 0.25 & 0.74 & 0.66 & 0.2 & 0.25 & 0.69 & 0.60 \\
\hline 0.2 & 0.5 & 0.75 & 0.67 & 0.2 & 0.5 & 0.70 & 0.63 \\
\hline 0.2 & 1 & 0.76 & 0.67 & 0.2 & 1 & 0.73 & 0.65 \\
\hline 0.2 & 2 & 0.77 & 0.68 & 0.2 & 2 & 0.77 & 0.68 \\
\hline 0.2 & 4 & 0.77 & 0.68 & 0.2 & 4 & 0.77 & 0.68 \\
\hline 0.2 & 6 & 0.77 & 0.68 & 0.2 & 6 & 0.77 & 0.68 \\
\hline 0.4 & 0.25 & 0.6 & 0.55 & 0.4 & 0.25 & 0.53 & 0.46 \\
\hline 0.4 & 0.5 & 0.61 & 0.56 & 0.4 & 0.5 & 0.54 & 0.48 \\
\hline 0.4 & 1 & 0.61 & 0.56 & 0.4 & 1 & 0.55 & 0.50 \\
\hline 0.4 & 2 & 0.62 & 0.56 & 0.4 & 2 & 0.62 & 0.56 \\
\hline 0.4 & 4 & 0.62 & 0.56 & 0.4 & 4 & 0.62 & 0.56 \\
\hline 0.4 & 6 & 0.62 & 0.56 & 0.4 & 6 & 0.62 & 0.56 \\
\hline 0.6 & 0.25 & 0.42 & 0.41 & 0.6 & 0.25 & 0.39 & 0.38 \\
\hline 0.6 & 0.25 & 0.43 & 0.42 & 0.6 & 0.25 & 0.41 & 0.41 \\
\hline 0.6 & 0.25 & 0.47 & 0.43 & 0.6 & 0.25 & 0.44 & 0.44 \\
\hline 0.6 & 0.25 & 0.48 & 0.44 & 0.6 & 0.25 & 0.48 & 0.44 \\
\hline 0.6 & 0.25 & 0.48 & 0.44 & 0.6 & 0.25 & 0.48 & 0.44 \\
\hline 0.6 & 0.25 & 0.48 & 0.44 & 0.6 & 0.25 & 0.48 & 0.44 \\
\hline
\end{tabular}

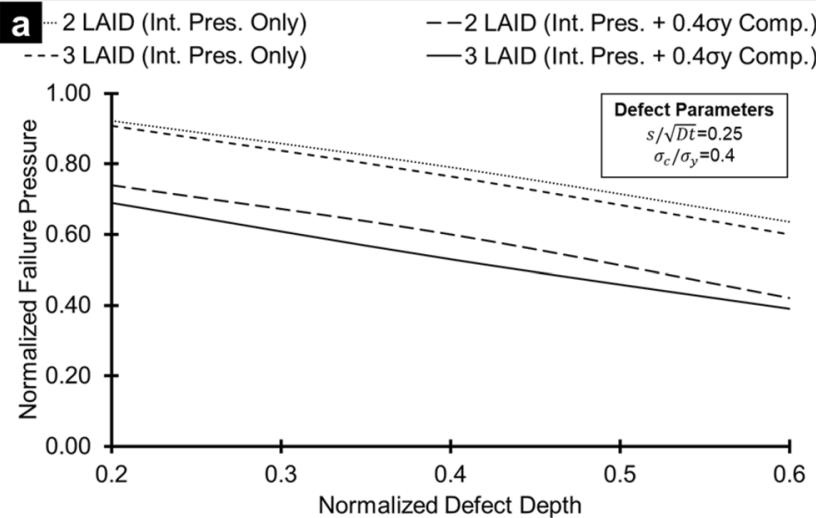

Fig. 6 a Normalized FEA failure pressure predictions under various normalized defect depth subjected to internal pressure only as well as both internal pressure and axial compressive stress, b normal-

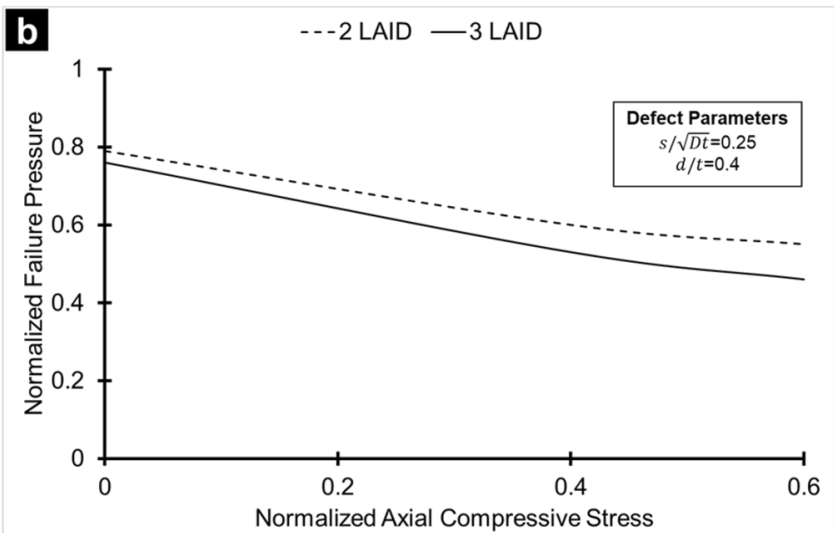

ized FEA failure pressure predictions under various normalized axial compressive stress 
these trendlines revealed a maximum difference of $6 \%$. Similarly, referring to the trendlines, when the multiple longitudinally aligned interacting defects are subjected to both internal pressure and axial compressive stress of $0.4 \sigma_{y}, 2$ LAID present higher failure pressure compared to 3 LAID. However, computation of the failure pressure percentage difference between these trendlines revealed a higher maximum difference of $12 \%$ compared to when subjected to internal pressure only. This suggests that axial compressive stress is detrimental with increasing number of longitudinally aligned interacting defects, as excessive loss of wall thickness reduces the ability to counteract the axial stress due to increase in internal pressure as well as the additional axial compressive stress.

Still referring to Fig. $6 a$, computation of the rate of decrement of multiple longitudinally aligned interacting defects subjected to internal pressure and axial compressive stress of $0.4 \sigma_{y}$ revealed that 2 LAID possesses a slightly higher rate of decrement of 0.080 normalized failure pressure drop for every 0.1 normalized defect depth, compared to 3 LAID which has a rate of decrement of 0.075 normalized failure pressure drop for every 0.1 normalized defect depth. Despite 2 LAID possessing a slightly higher rate of decrement compared to 3 LAID, failure pressures of 3 LAID are much lower when compared to equivalent defect geometric values. In addition, based on Fig. $6 a$, comparison of failure pressure percentage drop due to introduction of axial compressive stress of $0.4 \sigma_{y}$ revealed that for 2 LAID, there was a maximum drop of $34 \%$ (at $d / t=0.6$ ), while 3 LAID revealed a slightly higher maximum drop of $35 \%$ (at $d / t=0.6$ ).

Moving on to Fig. $6 \mathrm{~b}$, it is quite noticeable that the introduction of axial compressive stress (up to $0.4 \sigma_{y}$ ) resulted in a steep decrease with both 2 LAID and 3 LAID having rates of decrement of 0.048 and 0.058 normalized failure

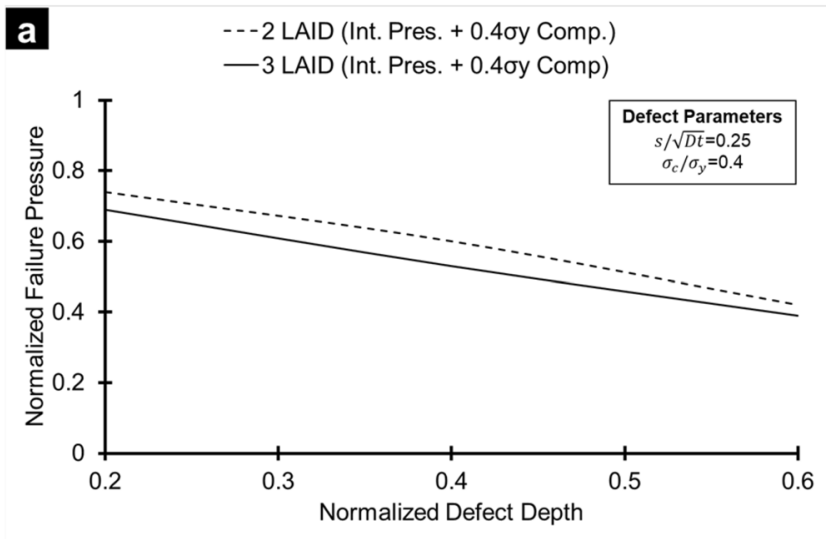

Fig. 7 a Normalized FEA failure pressure predictions under various normalized defect depth subjected to both internal pressure and a normalized axial compressive stress of $0.4, \mathbf{b}$ normalized FEA failure pressure drop for every 0.1 normalized defect depth, respectively. When the axial compressive stress increases from $0.4 \sigma_{y}$ to $0.6 \sigma_{y}$, the failure pressure decreases albeit with a lower rate of decrement. Both 2 LAID and 3 LAID have rate of decrements of 0.025 and 0.035 normalized failure pressure drops for every 0.1 normalized defect depth, respectively. In general, 3 LAID presented a much lower failure pressure compared to 2 LAID. Comparison of the failure pressure trendlines for these multiple longitudinally aligned interacting defects revealed a maximum failure pressure difference of $16 \%$ (at $0.6 \sigma_{y}$ ).

\subsection{Effects of corrosion defect depth}

Referring to Fig. 7a, it is observable that for multiple longitudinally aligned interacting defects subjected to axial compressive stress of $0.4 \sigma_{y}$, the failure pressure decreases as the corrosion defect depth increases. This is expected as the integrity of a pipe is highly reliant on the wall thickness; thus, the increase in corrosion defect depth (decrease in wall thickness) would directly affect the failure pressure. Comparison between the failure pressure of 2 LAID and 3 LAID subjected to axial compressive stress of $0.4 \sigma_{y}$ revealed that the failure pressure of 3 LAID is lower than that of 2 LAID. By comparing the trendlines of these multiple interacting defects subjected to axial compressive stress of $0.4 \sigma_{y}$, a maximum difference of $12 \%$ was obtained (at $d / t=0.4$ ). Similarly referring to Fig. $7 \mathrm{~b}$, and when subjected to axial compressive stress of $0.6 \sigma_{y}$, failure pressure of 3 LAID is lower than that of 2 LAID with a maximum difference of $16 \%$ (at $d / t=0.4$ ).

Computation of the rate of failure pressure decrement of multiple longitudinally aligned interacting defects revealed that when subjected to axial compressive stress of $0.4 \sigma_{y}, 2$ LAID has a failure decrement rate of 0.08

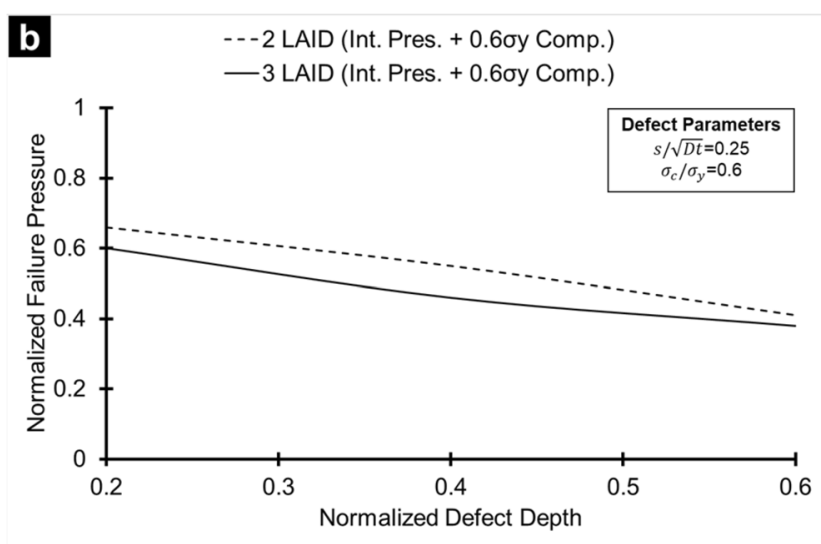

pressure predictions under various normalized defect depth subjected to both internal pressure and a normalized axial compressive stress of 0.6 
normalized failure pressure drop for every 0.1 normalized defect depth, while 3 LAID has a failure decrement rate of 0.07 normalized failure pressure drop for every 0.1 normalized defect depth. Referring to the graph in Fig. 7a with the aforementioned rates of decrement (for axial compressive stress of $0.4 \sigma_{y}$ ), it can be deduced that these rates are similar. Computation of the rate of failure pressure decrement of multiple longitudinally aligned interacting defects revealed that when subjected to axial compressive stress of $0.6 \sigma_{y}, 2$ LAID has a failure decrement rate of 0.063 normalized failure pressure drop for every 0.1 normalized defect depth, while 3 LAID has a failure decrement rate of 0.055 normalized failure pressure drop for every 0.1 normalized defect depth. These failure pressure decrement rates were found to be slightly lower than the previous case of $0.4 \sigma_{y}$. However, despite multiple longitudinally aligned interacting defects subjected to axial compressive stress of $0.4 \sigma_{y}$ having higher rate of decrement of failure pressure compared to when subjected to axial compressive stress of $0.6 \sigma_{y}$, it should be noted that the failure pressures of multiple longitudinally aligned interacting defects subjected to axial compressive stress of $0.6 \sigma_{y}$ are much lower when compared to $0.4 \sigma_{y}$ with equivalent defect geometric values.

\subsection{Effect of corrosion defect spacing}

Referring to Fig. $8 \mathrm{a}$, b, it is observable that for multiple longitudinally aligned interacting defects subjected to both axial compressive stresses of $0.4 \sigma_{y}$ and $0.6 \sigma_{y}$, as the defect spacing decreases, the failure pressure decreases. This is expected as defects that are close to each other have their regions of influence overlap, thus causing an increase in stress concentrations, eventually resulting in reduced failure pressure. Generally, it can be seen in Fig. $8 a, b$ that the

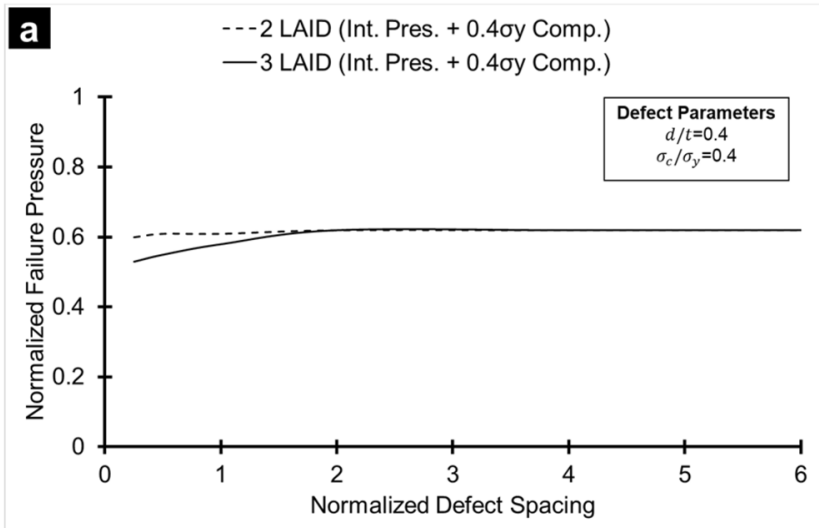

Fig. 8 a Normalized FEA failure pressure predictions under various normalized defect spacing subjected to both internal pressure and axial compressive stress of $0.4 \sigma_{y}$, b normalized FEA failure pressure failure pressures of 3 LAID are lower than those of 2 LAID. Comparison of failure pressures of multiple longitudinally aligned interacting defects subjected to axial compressive stress of $0.4 \sigma_{y}$ revealed a maximum difference of $12 \%$ (at $s / \sqrt{D t}=0.25$ ), while when subjected to axial compressive stress of $0.6 \sigma_{y}$, a maximum difference of $16 \%$ (at $s / \sqrt{D t}=0.25$ ) was revealed. In addition, it was determined that, regardless of the number of defects or the axial compressive stress, the failure pressure trends start to plateau past a normalized defect spacing of 2 which is similar to the findings of previous studies $[4,5]$. This suggests that past that critical value, interaction does not occur, and the defects can be assumed to be single and isolated.

It is important to note that each corrosion defect undergoes and imposes its own stress and strain disturbances. These stress and strain disturbances expand out of the corrosion defect and are known as regions of influence of the corrosion defects. Coalescence occurs when regions of influence of individual corrosion defects overlap [20].

Figure 9a illustrates the stress contours of corrosion defects with a normalized spacing of 0.25 . The figure reveals that the true UTS of the pipe material (red stress contour) has exceeded at the corrosion defect region. In addition, the region between the defects reveals coalescence of high stresses (stresses are close to the UTS of the pipe material). The red contour in Fig. $9 \mathrm{~b}$ allows for $\mathrm{a}$ clearer visualization of the coalescence of high stresses at the corrosion defects as well as the region between the defects. This phenomenon is, however, not seen with corrosion defects with a normalized spacing of 2 . Figure $10 \mathrm{a}$ illustrates the stress contours of corrosion defects with a normalized spacing of 2 . Similarly, the figure reveals that the true UTS of the pipe material (red stress contour) has exceeded at the corrosion defect region; however, as seen in Fig. 10b, the region of high stresses does not coalesce at

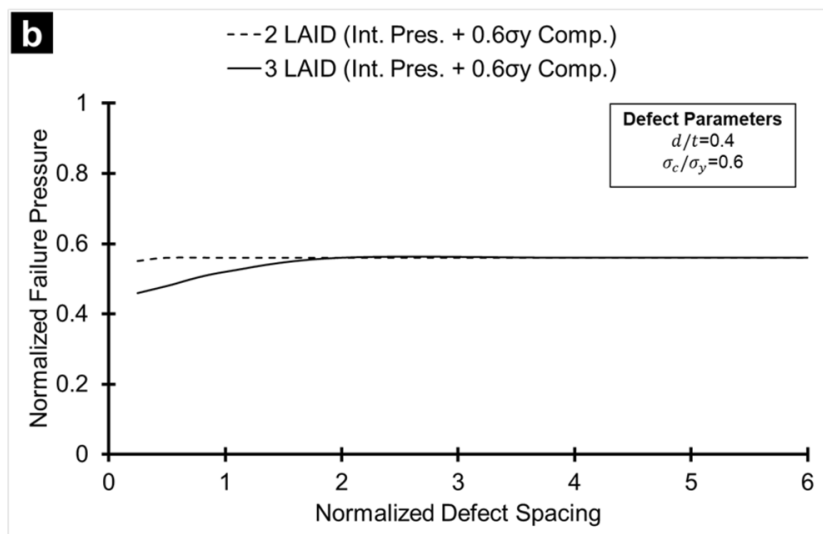

predictions under various normalized defect spacing subjected to both internal pressure and axial compressive stress of $0.6 \sigma_{y}$ 

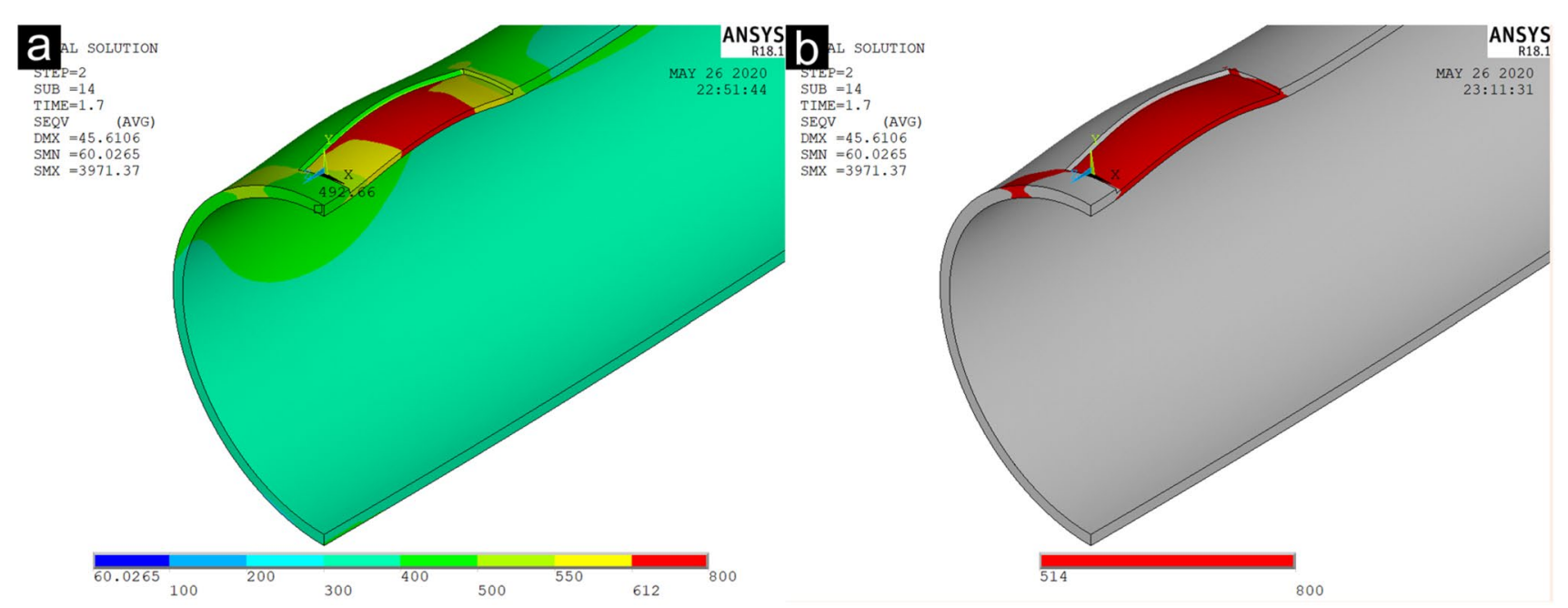

Fig. 9 a Stress contours of corrosion defects with a normalized spacing of 0.25 , b coalescence of UTS exceeding stress at the spacing between defects
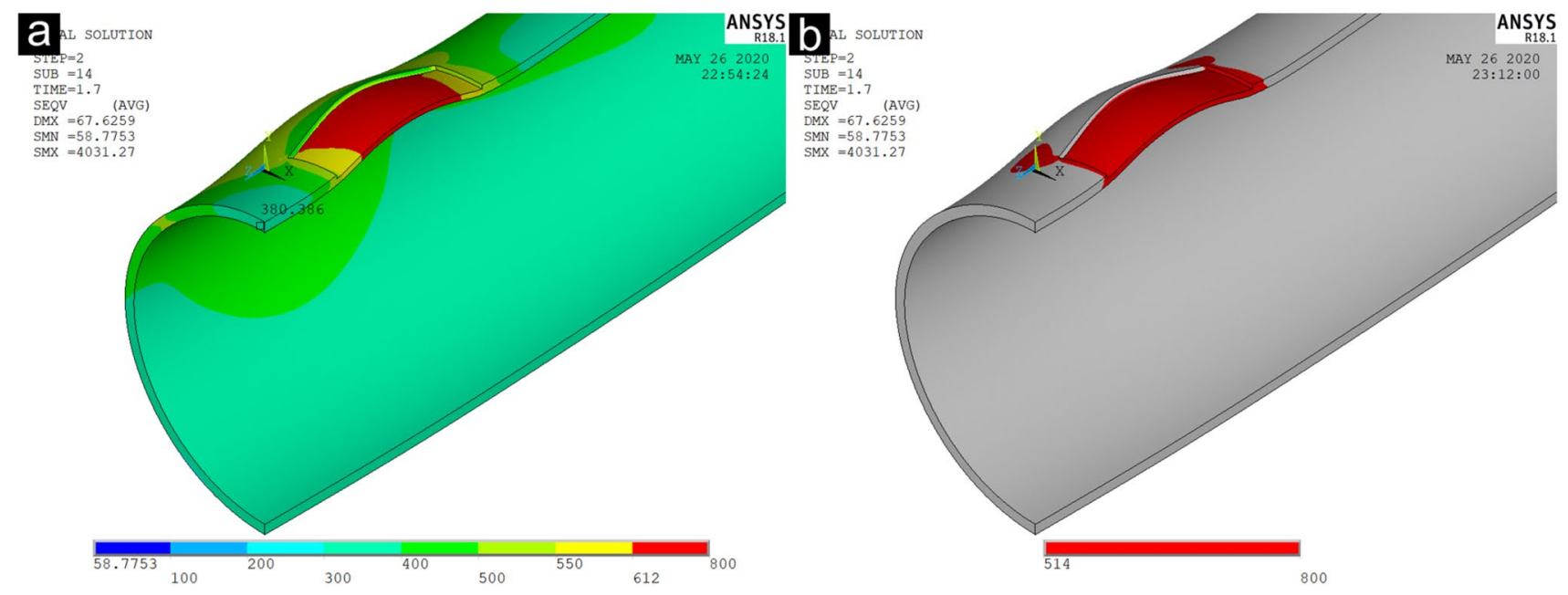

Fig. 10 a Stress contours of corrosion defects with a normalized spacing of 2, b lack of coalescence of UTS exceeding stress at the spacing between defects

the region between the defects. Hence, it can be deduced that stress coalescence does not occur when defects are sufficiently far apart.

\section{Conclusions}

FEM was developed to determine the failure pressure of pipe with multiple longitudinally aligned interacting corrosion defects subjected to both internal pressure and axial compressive stress. The corrosion defect depth, defect spacing, and axial compressive stress were varied to determine the failure pressure trends of multiple longitudinally aligned interacting corrosion defects. According to the results of FEA, the failure pressure trends for multiple longitudinally aligned interacting corrosion defects were similar, albeit 3 longitudinally aligned corrosion defects revealed lower failure pressures for all cases. For all cases, axial compressive stress is detrimental to the pipe failure pressure. When varying axial compressive stress, a maximum failure pressure difference of $16 \%$ (at $0.6 \sigma_{y}$ ) was observed between 2 and 3 defects. Besides that, it was determined that the increase in corrosion defect depth causes a decrease in failure pressure. When varying defect depth for 2 and 3 defects, maximum failure pressure differences of $12 \%$ (at $0.4 t \& 0.4 \sigma_{y}$ ) and $16 \%$ were observed (at $0.4 t \& 0.6 \sigma_{y}$ ). In addition, it was also determined that the decrease in corrosion defect spacing causes a decrease in failure pressure. When varying defect spacing for 2 and 3 defects, maximum failure pressure differences of $12 \%$

\section{SN Applied Sciences}


(at $0.25 \sqrt{D t} \& 0.4 \sigma_{y}$ ) and 16\% (at $0.25 \sqrt{D t} \& 0.6 \sigma_{y}$ ) were observed. Furthermore, it was determined that a normalized defect spacing of 2 is the interaction limit for multiple longitudinally aligned interacting corrosion defects as beyond that critical value, the failure pressure plateaus.

Funding This work was supported by Yayasan Universiti Teknologi PETRONAS, Malaysia [0153AA-E10].

\section{Compliance with ethical standards}

Conflict of interest The authors declare that they have no conflict of interest.

\section{References}

1. Kuppusamy CS, Karuppanan S, Patil SS (2016) Buckling strength of corroded pipelines with interacting corrosion defects: numerical analysis. Int J Struct Stab 16(09):1550063

2. Chen Y, Zhang H, Zhang J, Li X, Zhou J (2015) Failure analysis of high strength pipeline with single and multiple corrosions. Mater Des 67:552-557

3. Netto T, Ferraz U, Estefen S (2005) The effect of corrosion defects on the burst pressure of pipelines. J Constr Steel Res 61(8):1185-1204

4. Li X, Bai Y, Su C, Li M (2016) Effect of interaction between corrosion defects on failure pressure of thin wall steel pipeline. Int J Pres Ves Pip 138:8-18

5. AS DG (2015) Recommended Practice DNV-RP-F101 Corroded Pipelines

6. Ahammed M, Melchers R (1997) Probabilistic analysis of underground pipelines subject to combined stresses and corrosion. Eng Struct 19(12):988-994

7. Chauhan V, Swankie TD, Espiner R, Wood I (2009) Developments in methods for assessing the remaining strength of corroded pipelines. In: CORROSION 2009, NACE International

8. Chen Y, Zhang J, Zhang H, Liu X-b, Li X, Zhou J, Cao J (2015) Ultimate load capacity of offshore pipeline with arbitrary shape corrosion defects. China Ocean Eng 29:241-252

9. Xu LY, Cheng YF (2012) Reliability and failure pressure prediction of various grades of pipeline steel in the presence of corrosion defects and pre-strain. Int J Pres Ves Pip 89:75-84
10. Cosham A, Hopkins $P$ (2003) The assessment of corrosion in pipelines: Guidance in the pipeline defect assessment manual (PDAM) In: International colloquium reliability of high pressure steel pipelines

11. Cosham A, Hopkins P, Macdonald K (2007) Best practice for the assessment of defects in pipelines: corrosion. Eng Fail Anal 14(7):1245-1265

12. Bjørnøy O, Fu B, Sigurdsson G, Cramer E, Ritchie D (1999) Introduction and background to DNV-RP-F101 "Corroded Pipelines". In: The ninth international offshore and polar engineering conference, International Society of Offshore and Polar Engineers

13. Bjørnøy O, Sigurdsson G, Marley M (2001) Background and development of DNV-RP-F101 “Corroded Pipelines". In: The eleventh international offshore and polar engineering conference, International Society of Offshore and Polar Engineers

14. Belachew CT, Ismail MC, Karuppanan S (2015) Strength assessment of corroded pipelines: Finite element simulations and parametric studies. Int J Struct Stab Dyn 17:1750069

15. Institution BS (1999) Guide on methods for assessing the acceptability of flaws in metallic structures. British Standard Institution

16. Ikhsan I, Yoenoes A, Korda A, Soepriyanto A (2015) Effect of prestrain on the plasticity response of X65 pipeline steel. In: 36th the IIER international conference, Bali, Indonesia

17. Ma B, Shuai J, Liu D, Xu K (2013) Assessment on failure pressure of high strength pipeline with corrosion defects. Eng Fail Anal 32:209-219

18. Benjamin AC, Freire JLF, Vieira RD, Diniz JL, de Andrade EQ (2005) Burst tests on pipeline containing interacting corrosion defects. In: ASME 2005 24th international conference on offshore mechanics and arctic engineering, American Society of Mechanical Engineers, pp 403-417

19. Bjørnøy O, Sigurdsson G, Cramer E (2000) Residual strength of corroded pipelines, DNV test results. In: The tenth international offshore and polar engineering conference, International Society of Offshore and Polar Engineers

20. de Andrade EQ, Benjamin AC, Machado PR, Pereira LC, Jacob BP, Carneiro EG, Guerreiro JN, Silva RC, Noronha DB (2006) Finite element modeling of the failure behavior of pipelines containing interacting corrosion defects. In: 25 th international conference on offshore mechanics and arctic engineering, American Society of Mechanical Engineers, pp 315-325

Publisher's Note Springer Nature remains neutral with regard to jurisdictional claims in published maps and institutional affiliations. 